\title{
Federico TARRAGONI, L'Esprit démocratique du populisme. Une nouvelle analyse sociologique
}

\section{Frédérique Langue}

\section{(2) OpenEdition}

12 Journals

Édition électronique

URL : http://journals.openedition.org/ress/6664

DOI : $10.4000 /$ ress.6664

ISBN : $1663-4446$

ISSN : 1663-4446

Éditeur

Librairie Droz

Édition imprimée

Date de publication : 1 décembre 2020

Pagination : 251-254

ISSN : 0048-8046

Référence électronique

Frédérique Langue, « Federico TARRAGONI, L'Esprit démocratique du populisme. Une nouvelle analyse sociologique », Revue européenne des sciences sociales [En ligne], 58-2 | 2020, mis en ligne le 01 décembre 2020, consulté le 02 décembre 2020. URL : http://journals.openedition.org/ress/6664 ; DOI : https://doi.org/10.4000/ress.6664

Ce document a été généré automatiquement le 2 décembre 2020.

(c) Librairie Droz 


\title{
Federico TARRAGONI, L'Esprit démocratique du populisme. Une nouvelle analyse sociologique
}

\author{
Frédérique Langue
}

\section{RÉFÉRENCE}

Federico TARRAGONI, 2019, L'Esprit démocratique du populisme. Une nouvelle analyse sociologique, Paris, La Découverte, $372 \mathrm{p}$.

1 À des années-lumière des jugements à l'emporte-pièce véhiculés dans le débat public par les médias ou des questionnements sans fin et condamnations en filigrane en provenance de l'Université, le propos de l'ouvrage est affiché d'emblée dans son titre. Le populisme participe de la démocratie, il en est même un élément essentiel, si ce n'est incontournable. Rejoignant en cela une historiographie qui revendique avec Ernesto Laclau la "raison» de ce phénomène, voire la «séduction" qu'il opère sur ses partisans, l'ouvrage de Federico Tarragoni revisite un concept passablement galvaudé par ses thuriféraires comme par ses contempteurs, invitant à un «scepticisme radical ». Dans son introduction, « De quoi le populisme est-il le nom ? », il relève que la question a maintes fois été posée, sans pour autant conduire à une définition communément admise et encore moins consensuelle comme c'est le cas en Europe aujourd'hui. Le populisme est posé d'emblée comme un objet exemple de ces « fausses représentations véhiculées par les mésusages du langage»(p.11). De même, il procèderait d'un raisonnement simplificateur à l'endroit de réalités politiques hétéroclites, de partis d'extrême droite (Ligue italienne, Tea Party, RN en France, etc.) à une partie de l'extrême gauche (Podemos, Syriza, etc.), en passant par des leaders démagogues (Berlusconi, Trump, Sarkozy, etc.) ou encore des mouvements sociaux associés à la gauche radicale (tels les Indignés espagnols ou Nuit debout, voire les Gilets jaunes). Ses critiques sont tout aussi diverses et fluctuantes. Or, le concept, et "moment", renverrait à une réalité politique spécifique, radicale, contestataire et 
plébéienne, voire à un idéal-type (p. 25), ce que Tarragoni s'attache à démontrer tout au long de cet ouvrage, qu'il place résolument sous le «patronage » de Max Weber.

2 La méthode est radicale, fondée sur une déconstruction, tout à la fois d'un espace sémantique et d'un paradigme politique, en revenant sur certaines sources historiques, puis une «reconstruction» d'inspiration plus sociologique qu'historique (p. 29). La démonstration s'inscrit à l'encontre de "l'anathème populiste » (chapitre 1), celui-ci n'échappant pas à certaines formes de conformismes politiques ou intellectuels. Le chapitre 2 évoque ainsi « le populisme à rebours des idées reçues ", n'hésitant guère à souligner la fragilité de la " populologie » comme paradigme scientifique. De même s'y trouve soulignée l'interprétation en négatif de la « crise de la représentation » et de ses «menaces» (p.73), qui conduit à la représentation négative d'un peuple démagogue. Tarragoni insiste en fait sur les dynamiques qui président au développement de mouvements populistes. Il s'appuie à plusieurs reprises dans le livre sur l'exemple du péronisme, l'opposant aux pratiques mussoliniennes, et, plus largement, au retour en force des nationalismes et néofascismes qui tendent à s'approprier un "imaginaire plébéien ». Après un examen critique des "populismes à leur source » (chapitre 3), du concept "multistrate», des exemples russe des Narodniki et états-unien du People's Party, voire du "simulacre » boulangiste en France, sa réflexion met en exergue un "populisme réalisé ", celui de l'Amérique latine (chapitre 4). Au passage se trouve balayée l'objection césariste ou "caudilliste», marque d'un "sous-développement politique " pour nombre d'analystes européens. Le postulat majeur, revendiqué dans les premières pages à l'endroit principalement de l'Europe, demeure : quelle qu'en soit la définition retenue, le populisme présente des significations changeantes.

3 Même si sa « cible » demeure, comme Laclau l'avait souligné, l'opposition entre logique démocratique égalitaire et libéralisme économique propre aux démocraties représentatives, y compris dans leur déclinaison autoritaire, le populisme s'appuie sur l'apparition de mouvements sociaux hétérogènes. Et le leadership charismatique, voire l'acception "spécifiquement plébéienne " (p.27) de l'opposition peuple-élites le confortent. Cependant, le populisme se serait pas resté, en Amérique latine, une simple idéologie de crise (p. 215). Tout aussi présent dans les controverses politiques depuis la construction de l'État-nation sans pour autant verser dans un nationalisme exacerbé, le populisme dans ses déclinaisons latino-américaines ne méconnaît pas l'exercice du pouvoir. Il serait devenu une "philosophie cohérente d'action publique» (p. 217), ni atypique, ni un exemple parmi d'autres du phénomène populiste. Il pourrait être l'une des principales catégories de la modernité latino-américaine, fondées sur des formes de mobilisations qui ne recoupent pas celles des partis d'obédience marxiste ou des partis socialistes mais demeurent liées à l'action d'un leader.

4 Renversés dans la plupart des cas par des dictatures militaires (péronisme pour l'Argentine, populisme adeco de Betancourt au Venezuela, ou Estenssoro en Bolivie), les régimes populistes de la seconde moitié $d u x^{e}$ siècle s'inscrivent toutefois dans la lignée d'un "modèle continental " plébiscité, à la fois démocratique et intégrateur, porteur de droits sociaux et fondé sur le bastion électoral des classes moyennes et populaires. L'expérience populiste va ainsi des populismes «classiques » (caractérisation de la sociologie américaine) des décennies 1930-1960, populismes à tendance développementiste (en particulier dans le Brésil de Vargas, le Mexique de Cárdenas et l'Argentine de Perón) brisés par l'imposition de régimes dictatoriaux, au nouveau cycle ouvert notamment au début $\mathrm{du} \mathrm{xx}^{\mathrm{e}}$ siècle par les «transitions 
démocratiques ». Cette conjoncture signe le retour de la démocratie représentative mais également des politiques néolibérales et de nouveaux mouvements populaires, à dimension «participative " lors du «tournant à gauche » de l'année 2000, avec les gouvernements de Hugo Chávez (Venezuela), Evo Morales (Bolivie), et Rafael Correa (Équateur), jusqu'à une nouvelle étape, plus récente et caractérisée par le reflux (p. 221).

5 L'auteur aborde en effet ces expériences latino-américaines en tentant d'en déchiffrer l'énigme, à savoir la passion manifeste des classes populaires, syndicats ouvriers compris, pour ce modèle pourtant susceptible de verser dans l'autoritarisme tout en se différenciant clairement, sauf dans le cas de l'Estado novo, du fascisme européen. D'où les références aux travaux du sociologue italien Gino Germani, aux différents contextes qui président à la montée des populismes latino-américains, leur revirement suscitant la " colère populaire ", mais aussi à la caractéristique majeure de ces néo-populismes fondés non plus sur la modernisation du pays mais sur la rente. Entrent ici en jeu les ressources stratégiques (pétrole, gaz) mais aussi la récupération des exclus des politiques menées par les gouvernements précédents. Cependant, il ne s'agit plus d'un peuple représenté par des syndicats majoritaires, mais d'un peuple disposant d'un ancrage particulier dans les quartiers ou les communautés. D'où l'intérêt que revêtent, dans ce nouveau contexte, la démocratie participative et les mouvements populaires interclasses. Le travail n'est plus un mot d'ordre central, et la logique sociale de ces nouveaux populismes est autre. Il s'agirait même de revendiquer un "droit de préemption populaire sur la conception et la réalisation de la politique sociale " (p. 257), l'exemple le plus parlant étant celui du Venezuela. Les contradictions internes au modèle ne sont certes pas évacuées, et la justice sociale est finalement condamnée à l'échec, surtout lorsque les leaders charismatiques, tel Chávez, en viennent à disparaître. Les trois expériences mentionnées montrent indéniablement «une évolution hypertrophique de l'État et un autoritarisme croissant » (p. 259), ainsi qu'une polarisation inédite de l'opinion publique qui va bien au-delà des frontières nationales considérées, sans compter une idéologisation permanente des programmes politiques et de la communication officielle.

6 Dans ces conditions, et face à l'insatisfaction de demandes démocratiques, une "nouvelle théorie du populisme» (chapitre 5) est-elle possible ? Comment articuler crise, mobilisation et institutionnalisation dans cette " dynamique populiste »? Nous laisserons le lecteur découvrir les tenants et aboutissants de ces propositions qui revisitent un imaginaire renouvelé, celui de l'antagonisme peuple-élites, la politisation en démocratie des conflits par ces populismes et le rôle du leadership charismatique, ou encore la dénonciation du néo-libéralisme dans une perspective parfois fort éloignée de la « modernité » malgré l'institutionnalisation du modèle. L'hypothèse avancée est celle d'une relégation de la question démocratique et d'un étatisme allant croissant, qui exempte toutefois les dynamiques populistes de l'accusation de totalitarisme fréquemment avancée par ses détracteurs au profit d'une caractérisation « transitionnelle » et d'une instabilité politique persistante (p. 297).

7 Le sixième et dernier chapitre de cet ouvrage stimulant et contradictoire à la fois revient sur le populisme en Europe et la « latino-américanisation du vieux continent ». Tarragoni s'interroge à cet égard sur la pertinence du modèle aussi bien en Italie qu'en Grèce ou en Espagne, face à des mouvements souvent structurés qui, dans les "assemblées» tenues sur les places des grandes villes, dénoncent les politiques 
néolibérales et une démocratie corrompue par ses élites. Il considère enfin l'institutionnalisation manquée du "populisme hémiplégique » de la France insoumise en tant que " parti-mouvement » et son échec face à différentes formes de contestation populaire (p. 328). Les dérives du parti mélenchoniste sont ici passées au crible de l'analyse sociologique. Il est fait une place de choix à la responsabilité des idéologues dans cet échec, qu'il s'agisse d'économistes ou de philosophes (influence de Chantal Mouffe, collaboratrice de Laclau), sans compter la dérive personnaliste du leader « insoumis».

8 Tarragoni va toutefois prolonger le débat sur une interrogation alternative, celle que serait un «populisme européen" éloigné de l'«aveuglement idéologique». On partagera ou non son diagnostic quant à l'incompatibilité du modèle de la communauté européenne avec la démocratie et la faillite d'une politique commune ou encore l'émergence souhaitée de "nouveaux fronts populaires ». Il n'en reste pas moins que ce populisme toujours relié à un moment politique de transition est présenté comme "désormais le principal défi lancé à cette hégémonie ordo-libérale ». Comme «avenir démocratique » et facteur de «libertés positives » («Ce que peut le populisme», selon les termes de la conclusion), il demeure toutefois lié à des considérations politiques. Surtout, ce populisme que l'auteur appelle de ses vœux (plébéien, cosmopolitique et antisouverainiste) reste dépendant non seulement de "deuils conceptuels et stratégiques » dûment identifiés, mais également d'« un peuple qui reste à faire, sur la base de la division originaire du social entre dominants et dominés » comme le rappelle cette conclusion en forme de débat d'idées et d'« ego analyse ».

\section{AUTEURS}

\section{FRÉDÉRIQUE LANGUE}

CNRS-IHTP 